A. E. Jenks, Bureau of Ethnology, Washington, D. C.

John A. Just, Chemist, 116 West Castle street, Syracuse, N. Y.

Wm. D. Marks, The Art Club, Philadelphia, Pa.

Lucius Herbert Merrill, Professor of Biological

Chemistry, University of Maine, Orono, Maine.

Benjamin L. Miller, Johns Hopkins University,

Baltimore, Md.

Robert D. Murray, M.D., Marine Hospital Service,

Key West, Fla.

George J. Murdock, Mechanician and Inventor, 248

Sixth avenue, Newark, N. J.

Richard A. Parker, C.E., E.M., 4 P. O. Square,

Boston, Mass.

Thomas S. Perry, 312 Marlborough street, Back

Bay, Boston, Mass.

Wm. L. Prather, President of University of Texas, 1914 Nueces street, Austin, Texas.

Walter Merritt Riggs, Professor of Electrical Engineering, Clenıson College, Clemson College, S. C.

Fred W. Robins, Superintendent of Schools, Bethlehem, Pa.

George St. John Sheffield, Twin Elms Farm, Attleborough, Mass.

Charles H. Shinn, Inspector of Experiment Stations,

University of California, Berkeley, Cal.

Harvey F. Smith, Attorney-at-law, Clarksburg, W. Va.

Norman W. Storer, Electrical Engineer, 6109 Howe Street, Pittsburg, Pa.

W. S. Sutton, Professor of Science and Art of Education, University of Texas, 1812 Congress avenue, Austin, Texas.

E. A. H. Tays, Civil and Mining Engineer, San Jose de Gracia, Sinaloa, Mexico.

Alonzo P. Troth, Supervisor of Instruction in Science, High School, Leadville, Colo.

Andrew A. Veblen, Head of Department of Physics,

State University of Iowa, Iowa City, Iowa.

Wm. A. Wadsworth, Genesee, Livingston county, N. Y.

Dr. Walter F. Willcox, Professor of Economics, Cornell University, Ithaca, N. Y.

ADDRESS OF THE PRESIDENT OF THE AN. THROPOLOGICAL SECTION OF THE BRITISH ASSOCIATION FOR THE ADVANCEMENT OF SCIENCE.*

I.

Twenty-five years have passed since the British Association met in Glasgow. This is a long time to look back upon, and yet

\footnotetext{
* Glasgow meeting, 1901.
}

the period appears short when measured by the great advance which has taken place in almost all branches of knowledge. Anthropology has shared in the general progress. The discoveries made within its confines may not have been so startling, nor yet have had such a direct influence upon the material welfare of the peopie, as in the case of other fields of scientific study, but its development has been steady and continuous, and it has grown much in public estimation.

At the Glasgow meeting of the Association in 1876 anthropology held a subsidiary position. It only ranked as a department, although it gained a special prominence through having Alfred Russel Wallace as its chairman. It was not until several years later that it became one of the recognized sections of the Association, and attained the high dignity of having a letter of the alphabet allotted to it. But quite independently of its official status it has always been a branch of study which has been accorded a large amount of popular favor. The anthropological meetings have, as a rule, been well attended, and the discussions, although perhaps on certain occasions somewhat discursive, have never lacked vigor or animation. Professor Huxley, who presided over the Anthropological Department at the Dublin meeting in 1878 , ascribed the popularity of the subject to the many openings which it affords for wide differences of opinion between the exponents of its numerous branches, and to the innate bellicose tendency of man. As the representative of a country in which, according to the same high authority, this tendency is less strongly marked than elsewhere, and of a race which has so frequently and pointedly exhibited its abhorrence of vigorous language, $I$ trust that my presence here as president may not react unfavorably on the interest shown in the work of the Section. 
The present occasion might appear to be peculiarly appropriate for my taking stock of our anthropological possessions and summing up the numerous additions to our knowledge of ' $m$ an and his doings' which have been made during the century which has just passed. Such a task, however, is surrounded with so much difficulty that I shrink from undertaking it. The scope of the subject is enormous, and the studies involved so diverse and so varied that $I$ feel that it is beyond my power to give any comprehensive survey of its development in all its parts. I prefer therefore to confine my remarks to that province of anthropology within which my own work has been chiefly carried on, and from this to select a subject which has for some years held a prominent place in my thoughts. I refer to the human brain and the part which it has played in the evolution of man.

One of the most striking peculiarities of man, when regarded from the structural point of view, is the relatively great size of his brain. Although with one or two exceptions the several parts of the brain are all more or less involved in this special development, it is the cerebral hemispheres which exhibit the preponderance in the highest degree. This characteristic of the human brain is rendered all the more significant when we consider that the cerebral hemispheres cannot be looked upon as being primitive parts of the brain. In its earliest condition the brain is composed of three simple primary vesicles, and the cerebral hemispheres appear in a secondary manner in the shape of a pair of lateral offshoots or buds which grow out from the foremost of these primitive brain-vesicles.

The offshoots which form the cerebral hemispheres are found in all vertebrates. Insignificant in size and insignificant in functional value in the more lowly forms, a steady increase in their proportions is manifest as we ascend the scale, until the imposing dimensions, the complex structure, and the marvelous functional potentialities of the human cerebral hemispheres are attained. In their development the cerebral hemispheres of man rapidly outstrip all the other parts of the brain, until they ultimately usurp to themselves by far the greater part of the cranial cavity. To the predominant growth of the cerebral hemisphere is due the lofty cranial vault of the human skull; to the different degrees of development and to the different forms which they assume are largely due the variations in cranial outline in diff $ə r e n t$ individuals and different races-variations in the determination of which the craniologist has labored so assiduously and patiently.

I think that it must be manifest to every one that the work of the craniologist, if it is to attain its full degree of usefulness, must be founded upon a proper recognition of the relation which exists between the cranium and the brain, or, in other words, between the envelope and its contents.

The cranium expands according to the demands made upon it by the growing brain. The initiative lies with the brain, and in normal conditions it is questionable if the envelope exercises more than a very subsidiary and limited influence upon the form assumed by the contents. The directions of growth are clearly defined by the sutural lines by which the cranial bones are knit together; but these are so arranged that they admit of the expansion of the cranial box in length, in breadth and in height, and the freedom of growth in each of these different directions has in all probability been originally determined by the requirements of the several parts of the brain.

The base or floor of the cranium, supporting as it does the brain-stem or the parts which possess the greatest phylogenetic antiquity, and which have not under- 
gone so large a degree of modification in human evolution, presents a greater uniformity of type and a greater constancy of form in different individuals and different races than the cranial vault, which covers the more highly specialized and more variable cerebral hemispheres.

To what extent and in what directions modifications in the form of the cranium may be the outcome of restrictions placed on the growth of the brain it is difficult to say. But, broadly speaking, I think we may conclude that the influence which the cranium, under normal circumstances, independently exerts in determining the various head-forms is trifling.

When we speak, therefore, of brachycephalic or short heads and dolichocephalic or long heads, we are merely using terms to indicate conditions which result from individual or racial peculiarities of cerebral growth.

The brachycephalic brain is not molded into form by the brachycephalic skull; the shape of both is the result of the same hereditary influence, and in their growth they exhibit the most perfect harmony with each other.

Craniology has been called the 'spoiled child of anthropology.' It is supposed that it has absorbed more attention than it deserves, and has been cultivated with more than its share of care, while other fields of anthropology capable of yielding rich harvests have been allowed to remain fallow. This criticism conveys a very partial truth. The cranium, as we have seen, is the outward expression of the contained brain, and the brain is the most characteristic organ of man ; cranial peculiarities, therefore, must always and should always claim a leading place in the mind of the anthropologist; and this is all the more imperative, seeing that the brains of different races are seldom available for investigation, whilst skulls in the different museums may literally be counted by thousands.
Meantime, however, the craniologist lies buried beneath a mighty mountain of figures, many of which have little morphological value and possess no true importance in distinguishing the finer differences of racial forms. Let us take as an example the figures upon which the cephalic or length-breadth index of the skull is based. The measurement of the long diameter of the cranium does not give the true length of the cranial cavity. It includes, in addition, the diameter of an air-chamber of very variable dimensions which is placed in front. The measurement combines in itself, therefore, two factors of very different import, and the result is thereby vitiated to a greater or less extent in different skulls. A recent memoir by Schwalbe * affords instructive reading on this matter. One case in point may be given. Measured in the usual way, the Neanderthal skull is placed in the dolichocephalic class; whereas Schwalbe has shown that if the brain-case alone be considered it is found to be on the verge of brachycephaly. Huxley, many years ago, remarked that ' until it shall become an opprobrium to an ethnological collection to possess a single skull which is notbisected longitudinally,' in order that the true proportions of its different parts may be properly determined, we shall have no 'safe basis for that ethnological craniology which aspires to give the anatomical characters of the crania of the different races of mankind.' It appears to me that the truth of this observation can hardly be disputed, and yet this method of investigation has been adopted by very few craniologists.

It has become too much the habit to measure and compare crania as if they were separate and distinct entities and without a due consideration of the evolutionary

* 'Studien über Pithecanthropus erectus' (Dubois). Zeitschrift f. Morph. und Anthrop., Band I., Heft 1, 1899. 
changes through which both the brain and its bony envelope have passed. Up to the present little or no effort has been made to contrast those parts of the cranial wall or cavity which have been specially modified by the cerebral growth-changes which are peculiar to man. It may be assumed that these changes have not taken place to an equal extent, or indeed followed identically the same lines in all races.

Unfortunately our present knowledge of cerebral growth and the value to be attached to its various manifestations is not so complete as to enable us to follow out to the full extent investigations planned on these lines. But the areas of cerebral cortex to which man owes his intellectual superiority are now roughly mapped out, and the time has come when the effect produced upon the cranial form by the marked extension of these areas in the human brain should be noted and the skulls of different races contrasted from this point of view.

To some this may seem a return to the old doctrine of phrenology, and to a certain extent it is; but it would be a phrenology based upon an entirely new foundation and elaborated out of entirely new material.

It is to certain of the growth changes in the cerebrum which I believe to be specially characteristic of man, and which unquestionably have had some influence in determining head-forms, that I wish particularly to refer in this address.

The surface of the human cerebrum is thrown into a series of tortuous folds or convolutions separated by slits or fissures, and both combine to give it an appearance of great complexity. These convolutions were long considered to present no definite arrangement, but to be thrown together in the same meaningless disorder as is exhibited in a dish of macaroni. During the latter half, or rather more, of the century which has just ended it has, however, been shown by the many eminent men who have given their attention to this subject that the pattern which is assumed by the convolutions, while showing many subsidiary differences, not only in different races and different individuals, but also in the two hemispheres of the same person, is yet arranged on a consistent and uniform plan in every human brain, and that any decided deviation from this plan results in an imperfect carrying out of the cerebral function. In unraveling the intricacies of the human convolutionary pattern it was very early found that the simple cerebral surface of the ape's brain in many cases afforded the key to the solution of the problem. More recently the close study of the manner in which the convolutions assume shape during their growth and development has yielded evidence of a still more valuable kind. We now know that the primate cerebrum is not only distinguished from that of all lower mammals by the possession of a distinct occipital lobe, but also by having imprinted on its surface a convolutionary design which in all but a few fundamental details is different from that of any other order of mammals.

There are few matters of more interest to those anthropologists who make a study of the human skull than the relationship which exists between the cranium and the brain during the period of active growth of both. Up to the time immediately prior to the pushing out of the occipital lobe, or, in other words, the period in cerebral development which is marked by the transition from the quadrupedal type to the primate type of cerebrum, the cranial wall fits like a tight glove on the surface of the enclosed cerebrum. At this stage there would appear to be a growth antagonism between the brain and the cranial envelope which surrounds it. The cranium, it would seem, refuses to expand with a speed sufficient to meet the demands made upon it for the accommodation of the growing brain. In 
making this statement it is right to add that Hochstetter, in a carefully reasoned memoir, has recently cast doubt upon the reality of the appearances which have led to this conclusion, and at the recent meeting of the Anatomische Gesellschaft, in Bonn, Professor Gustaf Retzius,* one of the numerous observers responsible for the description of the early cerebrum upon which the conclusion is based, showed some inclination to waver in his allegiance to the old doctrine. This is not the time nor the place to enter upon a discussion of so technical a kind, but I may be allowed to say that whilst $I$ fully recognize the necessity for further and more extensive investigation in to this matter I do not think that Hochstetter has satisfactorily accounted for all the circumstances of the case.

When the occipital lobe assumes shape the relationship of the cranial wall to the enclosed cerebrum undergoes a complete change. The cranium expands so rapidly that very soon a wide interval is left between the surface of the cerebrum and the deep aspect of the cranial envelope within which it lies. This space is occupied by a soft, sodden, spongy meshwork, termed the subarachnôid tissue, and it is into the yielding and pliable bed thus prepared that the convolutions grow. At first the surface of the cerebral hemisphere is smooth, but soon particular areas of the cortex begin to bulge out and foreshadow the future convolutions. These suffer no growth restriction, and they assume the form of round or elongated elevations or eminences which rise above the general surface level of the cerebral hemisphere and break up its uniform contour lines in the same manner that mountain chains pro. trude from the surface of the globe.

As growth goes on, and as the brain

*Anatomische Gesellschaft, Bonn, May 28, 1901. Gustaf Retzius, 'Transitorische Furchen des Grosshirns.' gradually assumes a bulk more nearly in accord with the cavity of the cranium, the space for surface protrusions of this kind becomes more limited. The gyral elevations are now pressed together; they become flattened along their summits, and in course of time they acquire the ordinary convolutionary shapes. While this is going on the valleys or intervals between the primitive surface elevations become narrowed, and ultimately assume the linear slit-like form characteristic of the fissures. These changes occur shortly before birth, but are not fully completed until after the first few months of infancy. The final result. of this process is that the convolutions come into intimate relation with the deep aspect of the cranial wall and stamp their imprint upon it.

It is obvious that certain of the later changes which I have endeavored to portray might be ascribed to a growth antagonism between the brain and the enclosing cranium at this period. In reality, however, it is merely a process by which the one is brought into closer adaptation to the other - a using up, as it were, of superfluous space and a closer packing together of the convolutions-after the period of active cortical growth is past. Nevertheless the convolutionary pattern is profoundly affected by it, and it seems likely that in this process we find the explanation of the different directions taken by the cerebral furrows in brachycephalic and dolichocephalic heads.

The cortical elevations which rise on the surface of the early cerebrum are due to exuberant growth in localized areas. There cannot be a doubt that the process is intimately connected with the development of function in the districts concerned. We know that functions of different kinds are localized in different parts of the cortex, and when we see an area on the surface of the early cerebrum rise up in the form of 
an eminence, we may reasonably conclude that the growth in the area concerned is the structural foundation of what will become later on a center of functional activity of an acute kind.

A consideration of this matter gives the clue to the simple convolutions of the ape and the complex convolutions of man, and, further, it explains how the interrupted form of fissural development is one of the essential characteristics of the human brain as compared with the simian brain. Areas which rise up in the form of one long elevation on the surface of the ape's brain appear in the form of several eminences on the surface of the human brain, and fissures which appear in the form of long continuous slits in the simian cerebrum appear in the human cerebrum in several detached bits, which may or may not in the course of time run into each other and become confluent. All this is due to the greater definition, refinement and perfection of the functions carried on in the cerebral cortex of man. It is an index of a more complete 'physiological division of labor' in the human brain.

It is not necessary, for the purpose I have in view, to enter into any detail regarding the many points of difference which become evident when the cerebral surface of the ape is compared with that of man. It is more my purpose to indicate certain of the districts of cerebral cortex which have undergone a marked increase in the human brain-an increase which may be reasonably supposed to be associated with the high mental attributes of man. To us, at the present time, it is difficult to conceive how it was ever possible to doubt that the occipital lobe is a distinctive character of the simian brain as well as of the human brain, and yet at successive meetings of this Association (1860, 1861 and 1862) a discussion, which was probably one of the most heated in the whole course of its history, took place on this very point. One of our greatest authorities on animal structure maintained that the occipital lobe and the hippocampus minor-an elevation in its interior-were both peculiar to man and to him alone. Every one has read in the 'Water Babies' Charles Kingsley's delightful account of this discussion. Speaking of the Professor he says: "He held very strange theories about a good many things. He had even got up at the British Association and declared that apes had hippopotamus majors in their brains just as men have. What a shocking thing to say; for if it were so, what would become of the faith, hope and charity of immortal millions? You may think that there are other more important differences between you and an ape, such as being able to speak, and make machines, and know right from wrong, and say your prayers, and other little matters of that kind ; but that is a child's fancy." In the light of our present knowledge we can fully understand Professor Huxley closing the discussion by stating that the question had 'become one of personal veracity.' Indeed, the occipital lobe, so far from being absent, is developed in the ape to a relatively greater extent than in man, and this constitutes one of the leading positive distinctive characters of the simian cerebrum. Measured along the mesial border, the percentage length of the occipital lobe to the total length of the cerebrum in the baboon, orang and man is as follows:

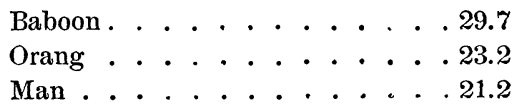

But these figures do not convey the full extent of the predominance of the occipital lobe in the ape. The anterior border of the lobe grows forwards beyond its proper limits, and pushes its way over the parietal lobe which lies in front, so as to cover over a portion of it by an overlapping lip termed 
the occipital operculum. There is not a trace of such an arrangement in the human brain, and even in the anthropoid ape the operculum has become greatly reduced. Indeed,in man there is exactly the reverse condition. The great size of the parietal lobe is a leading human character, and it has partly gained its predominance by pushing backwards so as to encroach, to some extent, upon the territory which formerly belonged to the occipital lobe.* A great authority $\dagger$ on the cerebral surface refers to this as a struggle between the two lobes for surface extension of their respective domains. "In the lower apes," he says, " the occipital lobe proves the victor; it bulges over the parietal lobe as far as the first annectant gyrus. Already in the orang, the occipital operculum has suffered a great reduction; and in man the victory is on the side of the parietal lobe, which presses on the occipital lobe and begins, on its part, to overlap it." Now that so much information is available in regard to the localization of function in the cerebral cortex, and Flechsig has stimulated our curiosity in regard to his great 'association areas' in which the higher intellectual powers of man are believed to reside, it is interesting to speculate upon the causes which have led to the pushing back of the scientific frontier between the occipital and parietal cerebral districts.

The parietal lobe is divided into an upper and a lower part by a fissure, which takes an oblique course across it. Rudinger, $\ddagger$ who studied the position and inclination of this fissure, came to the conclusion that it

* It is necessary to emphasize this point, because in Wiedersheim's 'Structure of Man' we are told that in man there is a preponderance of the occipital lobe, and that the parietal lobe is equally developed in man and anthropoids.

$\dagger$ Eberstaller, Wiener Medizinische Blätter, 1884, No. 19, p. 581 .

‡'Beiträge zur Anatomie und Embryologie,' als Festgabe Jacob Henle, 1882. presents easily determined differences in accordance with sex, race and the intellectual capacity of the individual. He had the opportunity of studying the brains of quite a number of distinguished men, amongst whom were Bischoff of Bonn, Döllinger of Munich, Tiedemann of Heidelberg, and Liebig of Munich, and he asserts that the higher the mental endowment of an individual the greater is the relative extent of the upper part of the parietal lobe.

There is absolutely no foundation for this sweeping assertion. When the evolutionary development of the parietal part of the cerebral cortex is studied exactly the reverse condition becomes manifest. It is the lower part of the parietal lobe which in man, both in its early development and in its after-growth, exhibits the greatest relative increase. Additional interest is attached to this observation by the fact that recently several independent observers have fixed upon this region as one in which they believe that a marked exuberance of cortical growth may be noted in people of undoubted genius. 'Thus Retzius has stated that such was the case in the brains of the astronomer Hugo Gyldén, * and the mathematician Sophie Kovalevsky ; $\dagger$ Hansemann $\ddagger$ has described a similar condition in the brain of Helmholtz ; and Guszman $\S$ in the brain of Rudolph Lenz, the musician. Some force is likewise added to this view by Flechsig, who, in a recent paper, $\|$ has called atten-

* Retzius, Biologische Untersuchungen, neue Folge, VII., 1898, 'Das Gehirn des Astronomen Hugo Gyldéns.'

† Retzius, Biologische Untersuchungen, neue Folge, IX., 1900, 'Das Gehirn der Mathematikerin Sonja Kovalevsky.'

$\ddagger$ Hansemann, Zeitschrift für Psychologie und Physiologie der Sinnesorgane, Band XX., Heft 1, 1899, ' Ueber das Gehirn von Hermann v. Helmholtz.'

3. Josef Guszman, Anatomischer Anzeiger, Band XIX., Nos. 9 and 10, April, 1901, 'Beiträge zur Morphologie der Gehirnoberfläche.'

|| Flechsig, 'Neue Untersuchungen über die Markbildung in den menschlichen Grosshirnlappen,' Neurologisches Centralblatt, No. 21, 1898. 
tion to the fact that within this district there are located two of his so-called 'Terminalgebiete,' or cortical areas, which attain their functional powers at a later period than those which lie around them, and which may therefore be supposed to have specially high work to perform.

Without in any way desiring to throw doubt upon the observations of these authorities, I think that at the present moment it would be rash to accept, without further evidence, conclusions which have been drawn from the examination of the few brains of eminent men that have been described. There cannot be a doubt that the region in question is one which has extended greatly in the human brain, but the association of high intellect with a special development of the region is a matter on which $I$ must confess I am at present somewhat sceptical.

But it is not only in a backward direction that the parietal lobe in man has extended its territory. It has likewise increased in a downward direction. There are few points more striking than this in the evolution of the cerebral cortex of man. In order that I may be able to make clear the manner in which this increase has been hrought about, it will be necessary for me to enter into some detail in connection with the development of a region of cerebral surface termed the insular district. The back part of the frontal lobe is also involved in this downward extension of surface area, and, such being the case, it may be as well to state that the boundary which has been fixed upon as giving the line of separation between the parietal and frontal districts is purely artificial and arbitrary. It is a demarcation which has no morphological significance, whilst from a physiological point of view it is distinctly misleading.

\section{J. Cunningham.}

\section{SCIENTIFIC BOOKS.}

Die Partiellen Differential-Gleichungen der Mathematischen Physik. Nach Riemann's Vorlesungen. In vierter Auflage. Neu bearbeitet von Heinrich Weber, Professor der Mathematik an der Universität Strasburg. Braunschwieg, Druck und Verlag von Friedrich Vieweg und Sohn. 1900, 1901. Erster Band, pp. xvi +506 ; Zweiter Band, pp. xi +527 . The appearance of this new and greatly enlarged edition of the work founded on Riemann's lectures will be welcomed with delight by every student of the mathematico-physical sciences. Those acquainted with the preceding capital edition of Hattendorff do not need to be reminded of the high model of excellence in exposition he set. Professor Weber has not only amplified this model, but he has fairly canonized it, placing before the student a glorified summary of the physical concepts and the mathematical methods on which the great progress of the nineteenth century in physical science rests.

It is a good sign of the times that many eminent European mathematicians are reverting to the example set by the illustrious Gauss and followed with such signal success by Riemann, Clebsch, Kirchhoff and others. The advantages to be gained by the pure and by the applied mathematician in following such an example are mutual so far as existing science is concerned, while the better understanding of one another's work which results therefrom makes it easier to secure that sort of cooperation essential to rapid and permanent advances. The mathematical physicist is, therefore, under deep obligations to Professor Weber for the admirable presentation he has given us of the more important and more difficult branches of mathematical physics.

The reader who may be unacquainted with the earlier editions of this work should be warned against supposing it to be a treatise on any one of the subjects considered. Its great merit lies in the fact that while not a treatise, it states the salient principles and essential mathematical features of many branches of physics with a clearness and with an attractiveness rarely attained in formal treatises. No previous work, so far as we are 